\title{
Launch of the Contemporary Pediatric Dentistry: Dream, Vision, Plan, and Reality
}

\author{
"Make things happen! All good things start with a dream. \\ The dream becomes a vision. The vision becomes a plan. The plan becomes a reality!"
}

This was my main philosophy of launching the new journal, Contemporary Pediatric Dentistry. I am very honoured and pleased to take the first step of my dream and to celebrate the launch and first issue of Contemporary Pediatric Dentistry, a new international, scientific, open access, online-only publication that aims to serve as a forum for scientifically based information in pediatric dentistry, with the intention of continually expanding the knowledge base in this area. We aim to promote the highest standard of education, practice and research in pediatric dentistry worldwide. This new journal aims to provide an open-access forum for the exchange of information about contemporary, new, and significant research in pediatric dentistry throughout the world. Thus, the Contemporary Pediatric Dentistry's broad readership consists of pediatric dentists, dentists, and all academicians, researchers, specialists, and general practitioners interested in pediatric dentistry.

The journal will be published in three times in every year (April, August, and December), and its publication language is English. Articles published in this journal are evaluated in an independent and fair, double-blinded peer-reviewed fashion.

I hope that Contemporary Pediatric Dentistry will become the primary platform for researchers to share findings and discuss all aspects of pediatric dentistry in the development of future innovations that will benefit the international community.
We are now enjoying publishing the First Issue of Contemporary Pediatric Dentistry. Our journal received 24 submissions in just three months since its establishment in 24 August 2020. In our first issue, we have now published a total of 7 articles including original research, review articles and case reports from 5 different countries.

I take this opportunity to thank our Authors, Associate Editors, Reviewers, and all of colleagues who are volunteered to contribute to the success of the journal. On behalf of the Editorial Board, I would also like to extend my warmest welcome to the readers of Contemporary Pediatric Dentistry. I owe a special thank to Dr. Kaan Sağtaş, the Production Editor and a good friend, for his really hardworking and altruistic job during the establishment of this journal.

I feel very excited to see the development of this journal. Together, let's dream and make the Contemporary Pediatric Dentistry as leading journal in this area!

If you have any questions, support, suggestions or concerns, please feel free to contact to me personally.

Thank you!

Best regards, 